\title{
From introduction to phonemic symbols to development of transcription skills: A case study in the English Department at Univer- sity of Tuzla
}

\author{
Sanel Hadžiahmetović Jurida \\ English Department \\ Faculty of Philosophy \\ University of Tuzla
}

\begin{abstract}
The present study portrays some of the key aspects of connected speech in English, as adopted by 42 native Bosnian/Croatian/Serbian-speaking undergraduate students of English in the English Department, University of Tuzla, in the academic year 2013/2014. More specifically, the study shows how successfully these students developed their transcription skills in English, particularly when it comes to the use of diacritics for dental, velarised, and syllabic consonants of English, as well as for aspirated and unreleased (unexploded) English plosives. In addition, the study focuses on the coalescent type of assimilation. Connected speech (also known as rapid, relaxed, casual, or fluent speech) is characterised by a number of phonetic phenomena. The paper also analyses the level to which students enrolled in the English Department in Tuzla have developed a sense of elementary terms in this field, an understanding of the English sound system, and generally speaking, to what extent they developed their broad and narrow transcription skills.
\end{abstract}

Key words: connected speech; phoneme; allophone; transcription; aspects of connected speech; coalescent assimilation; diacritics; aspirated and unreleased plosives; dentalisation; velarisation; syllabic consonants.

\section{Introduction}

The objective of the study is to portray some of the key aspects of connected speech in RECEIVED PRONUNCIATION, as adopted by native Bosnian/Croatian/Serbian-speaking undergraduate students of English in the English Department, University of Tuzla, Bosnia and Herzegovina. This study examined a 
total of 42 students enrolled in the English Department in the academic year $2013 / 2014$.

More specifically, the study shows how successfully these students developed their transcription skills in English after taking a two-semester course in English Phonetics and Phonology. The paper specifically looks at particular diacritics used for the transcription of a number of particular allophones considered to be found most frequently used in everyday English. The paper outlines the diacritics for dental, velarised, and syllabic consonants of English, as well as for aspirated and unreleased (unexploded) English plosives.

The second part of the paper focuses on the phenomena typical of connected speech, such as coalescent assimilation. Particular attention is given to aspiration, unreleased plosives, dentalisation, velarisation and syllabic consonants. Each of the respective topics includes a discussion and analysis of the results, and may serve as a starting point for further research in this field.

As for methodology, a brief diagnostic test was administered at the very beginning of the academic year in order to determine the students' level of English Phonetics and Phonology command. The students were presented with two groups of questions. The first group was more theory-orientated, whereas the second group of questions focused on more practical issues, such as identification of vowels and consonants, including the distinction between sounds and letters, identification of sounds, stressed syllables, identifying words from their respective transcriptions, etc.

Following the introduction, the theoretical framework will provide more details on the topic of the present research. The methods of data collection and methodology used in the study are accompanied by the results and the discussion. The final section of the paper presents the conclusions.

\section{Theoretical Background}

As Lintunen (2005) points out, phonemic transcription is a teaching method that has traditionally been used for foreign language learners of English, especially at advanced levels. Gomes de Matos (2002: 314) marked transcription reading skills as one of the fundamental abilities that every foreign language learner should master and certainly most books for EFL learners include phonemic symbols in vocabulary sections. Phonemic symbols are a necessity for writing about pronunciation, but they are often neglected in teaching although there is considerable variation between levels and individual teachers. Often the situation depends on how effective the teachers themselves find this method.

Generally speaking, phonemic transcription is likely to be very beneficial for learners who are accustomed to a close phoneme-grapheme correspondence in their native language when they want to learn a language with more complicated 
grapheme-to-phoneme rules. Thus a good example can be provided by Bosnians and Herzegovinians learning English. Bosnian/Croatian/Serbian orthography follows the one-to-one correspondence between phonemes and sounds with some minor exceptions (e.g. there is no single grapheme for the velar nasal / $\mathrm{y} /$ ). Therefore the relationship between the spelling and pronunciation of English is not straightforward for Bosnian and Herzegovinian learners of English. Lintunen further argues that phonemic transcription provides an intermediate stage which should make learners more aware of the phonemic level of language, stating that improved phonemic awareness, in turn, is assumed to aid learners' pronunciation skills (e.g. Wells, 1996).

Any discussion of connected speech requires at least a minimum of introduction to some basic concepts and terminology found in the field of phonetics and phonology. The following paragraphs focus on some fundamental principles of phonetics and phonology, as seen by a number of phoneticians and phonologists, and include the following:

- Phonetics and phonology

- Phoneme and allophone

- Transcription: broad and narrow

- Phonemic and phonetic symbols

Crystal (1997: 289) defines phonetics as the science that studies the characteristics of human sound-making, particularly those sounds used in speech, and provides methods for their description, classification and transcription. This paper primarily deals with the latter, attempting to outline some aspects of connected speech in Received Pronunciation (RP) concerning a select few English consonants, including the examples of assimilation and intrusion and linking.

Crystal (1997: 290) states that the aim of phonology, as a linguistic discipline studying the sound systems of languages, is to demonstrate the patterns of distinctive sound found in a language, and to make as general statements as possible about the nature of sound systems in the languages of the world. Phonology is therefore often referred to as 'FUNCTIONAL PHONETICS' given the fact that it is primarily concerned with a number of functions of sounds in specific languages. This paper deals with segmental phonology, primarily concerned with the analysis of speech into segments (phonemes).

According to Roach (1992: 80), phoneme is the fundamental unit of phonology, which has been defined and used in many different ways. Crystal (1997: 287) sees the phoneme as the minimal unit in the sound system of a language, according to traditional phonological theories. Roach argues that virtually all theories of phonology hold that spoken language can be broken down into a string of sound units (phonemes), and that each language has a small, relatively fixed set of these phonemes. 
As Celce-Murcia et al. (1996: 37) put it, linguists find it useful to focus on those sound differences that distinguish words (i.e. sounds called phonemes) and sounds that are perceptibly different but do not distinguish words (i.e. sounds called allophones). To illustrate the concepts of phoneme and allophone, CelceMurcia et al. (1996) refer to a group of North American tourists visiting a London restaurant and asking for butter. Surely their request will be understood, and the desired end result obtained, but no sooner will the word butter be spoken than the tourists will be recognised as North Americans. Why? Celce-Murcia et al. (1996) further explain that the lay explanation is that the tourists have an American accent, however, linguists explain that the allophone of $/ \mathrm{t} /$ that the North American English speakers use in the word butter (an alveolar flap [I]) is quite different from the allophone $[t]$ used by their London counterparts.

Crystal (1997: 287) states that each language can be shown to operate with a relatively small number of phonemes - some languages have as few as 15 phonemes, others as many as 80 . Another important fact to observe is that no two languages have the same phonemic system. According to Crystal, sounds are considered to be members of the same phoneme if they are phonetically similar, and do not occur in the same environment (they are in complementary distribution), or if they do, the substitution of one sound for the other does not cause a change in meaning (they are said to be in free variation). On the other hand, a sound is said to be 'phonemic', if its substitution in a word does cause a change in meaning. Therefore, in phonemic transcription, only phonemes are given symbols (compared with phonetic transcription, where different degrees of allophonic detail are introduced, depending on one's purpose). This paper actually intends to look precisely at some of those details - particular allophones of some of the English consonants.

Josipović (1999: 26) says that another way to define the phoneme is to say that it is a family of sounds. If we look at one of the examples, the phonetic quality of the initial consonant in the word park is not the same as the quality of the sound /p/ in the word spark. In the case of the former, it is articulated with full audible breath (aspirated), and in the latter it is not the case. Josipović further argues that, since there are countless other examples to illustrate this, the phoneme can be regarded as a set of phonetically similar sounds. The different realisations of a phoneme are referred to as its allophones.

Ladefoged (2001: 272) also defines the allophone as a variant of a phoneme, and gives the main features of the allophones of a particular phoneme, as follows:

- They do not change the meaning of a word,

- They are all very similar to one another, and

- They occur in phonetic contexts different from one another (e.g., syllable initial as opposed to syllable final). 
In conclusion, Ladefoged (2001: 23) defines phonemes as two sounds that can be used to differentiate words. He argues that there must be a phonemic difference if two words (such as right and white, or cat and bat) differ in only a single sound.

According to Roach (1992: 115), in present-day usage, transcription is the writing down of a spoken utterance using a suitable set of symbols. In its original meaning, he argues, the word implied converting from one representation (e.g., written text) into another (e.g., phonetic symbols). Transcription exercises are a long-established exercise for teaching phonetics. Generally speaking, there are many different types of transcription: the most fundamental division that can be made is between PHONEMIC (BROAD) and PHONETIC (NARROW) TRANSCRIPTION. In the case of the former, the only symbols that may be used are those which represent one of the phonemes of the language, and extra symbols are excluded. In a phonetic transcription, the transcriber may use the full range of phonetic symbols if these are required. A narrow phonetic transcription is one which carries a lot of fine detail about the precise phonetic quality of sounds, while a broad phonemic transcription gives a more limited amount of phonetic information.

Crystal (1997: 393) defines transcription as a method of writing down speech sounds in a systematic and consistent way (also known as a notation or script). Square brackets ([]) enclose phonetic (narrow) transcription, whereas slant brackets $(/ /$, oblique lines) enclose phonemic (broad) transcription. In any transcription (whether phonemic or phonetic), each distinguishable sound is given its own symbol. The whole range of available phonetic symbols is known as a 'phonetic alphabet'. The most widely used such alphabet is the INTERNATIONAL PHONETIC ALPHABET.

Depending on how detailed transcription we would like to have, two types of transcription may be distinguished: phonemic and phonetic. In phonemic or broad transcription, the symbols used stand for phonemes (also known as phonemic symbols), e.g. lake /lerk/, mistake /misterk/. A phonemic transcription of a word or a phrase, as already indicated, is given in slant brackets - / /. For these purposes, the IPA offers the vowel chart and the consonant chart, both designed to help transcribers working with all world's languages, not just English.

A phonetic transcription, on the other hand, is used to indicate particular details of the production of any particular sound by using special symbols, also referred to as diacritics, e.g. an aspirated $/ \mathrm{t} /$ is represented as $\left[\mathrm{t}^{\mathrm{h}}\right]$ in take, an unreleased $/ \mathrm{k} /$ is represented as [k] in act, the alveolar /n/ becomes dental is represented as $[\mathrm{n}]$ in tenth, etc. 


\section{Methodology}

As already introduced, the present study examined a total of 42 students who enrolled in the English Department at the Faculty of Philosophy of the University of Tuzla in the academic years 2013/2014. The data were collected for the study from separate tests for transcription at two points during the course to observe the students' development in the tasks assigned.

The first point of data collection was a brief diagnostic test that was administered at the beginning of the academic year to test the students' transcription skills, and, additionally, to determine their general command in English Phonetics and Phonology. At this point, the students were asked to provide answers to a number of questions, including the distinction between sounds and letters, identification of sounds, stressed syllables, identifying words from their respective transcriptions, etc.

The second testing point was the final examination where a significant portion of the test focused solely on broad and narrow transcription of words given in spelling, where the students produced broad and narrow transcription for the words carefully selected for these purposes, which were given to them in spelling only. The final examination followed the completion of the two-semester course in English Phonetics and Phonology. Afterwards their errors were analysed. The accepted transcriptions were the standard pronunciations proposed by Wells (2001).

Each of the subsections of Section 4 of this paper includes the examples of words that served for testing purposes, some actual transcriptions produced by the students (correct and incorrect), a graphic presentation of the results, indicating the extent to which the students adopted the variety of symbols they were taught over the two semesters, focusing on broad and narrow transcription of carefully selected words and phrases, including diacritics elaborated on in Section 4 of the paper.

In doing so, the author of the paper did keep in mind the fact that students enrolling in the English Department come indeed from a variety of backgrounds, various secondary and high schools, most of whom had English as their first foreign language in their secondary education, albeit with very little or rather limited knowledge of English Phonetics and Phonology whatsoever, primarily because this field is not given due attention in secondary English education.

\section{Results and Discussion}

Generally speaking, looking at the diagnostic test which served as a starting point for this completion of this study, it can be said that there was very little response when it comes to the theory-oriented questions. In terms of identifying words from 
their respective transcriptions, (the second group of questions), most students could easily identify London when presented with the broad transcription of the UK capital. However, most, in fact all of them had a problem identifying one of the major Swedish cities of Gothenburg.

Another major issue faced by the students was their inability to identify, for instance, short and long vowels, which was intended to be one of the easiest diagnostic questions. A rather small percentage of the students tested were able to identify /i:/ in words like bead, peak and bead. On the other hand, in choosing the odd sound, the students showed better success, thus $95 \%$ of them identifying do as the odd word in the series of words including go, no, so and do.

In short, the conclusion here is that there is very little, if any at all, focus at the secondary school level on matters we deal with on English Phonetics and Phonology in general. The following pages and sections will clearly illustrate (statistically, too) how successful the students were after the completion of the two-semester course over in the course of which there were extensive exercises focusing on the English sound system, broad and narrow transcription of words and phrases etc.

For each of the following subsections of the paper, the students were asked to produce both broad and narrow transcription of the words. Examples will be presented in the spelling given to students, and will be followed by some actual transcriptions produced by the students (correct and incorrect), including a graphic presentation of the results, indicating the extent to which the students adopted the variety of symbols they were taught over the two semesters, focusing on broad and narrow transcription of carefully selected words and phrases, including diacritics elaborated on in this Section of the paper.

\subsection{Aspiration}

Examples of words given to students in spelling only, including the actual transcription as produced by the students, both broad and narrow:

i): $\quad$ correctly

word broad transcription

1. tick

2. supply

3. pack

4. spelt /tik/

/ so'pla1/

/pæk/

/spelt/ narrow transcription

$\left[\mathrm{t}^{\mathrm{h}} \mathrm{ik}\right]$

[səp ${ }^{\mathrm{h}}$ la1]

[phæk]

[spett]

and 
ii) incorrectly

word broad transcription

5. tick / / tk/

6. pet

7. supply

8. pack

9. spelt /pet/

/sa'plai/

/pek/

/spelt/ narrow transcription

$\left[\mathrm{t}_{1} \mathrm{k}^{\mathrm{h}}\right]$

[pet $\left.{ }^{\mathrm{h}}\right]$

[səpla1]

[pek]

[sp $\left.{ }^{\mathrm{h}} \mathrm{elt}\right]$

Table 1 below shows that $69.1 \%$ of the students successfully identified aspirated plosives $/ \mathrm{p} /, / \mathrm{t} /$ or $/ \mathrm{k} /$ in the words shown above.

\begin{tabular}{|c|c|c|c|}
\hline Academic Year & $\begin{array}{c}\text { No. of sub- } \\
\text { jects tested }\end{array}$ & YES & \% \\
\hline $2013 / 2014$ & 42 & 29 & 69.1 \\
\hline
\end{tabular}

Table 1. Identification of aspirated plosives

Examples 5 through 9 relate to the remaining 13 students who failed to identify aspiration for a variety of reasons. In examples 5 and 6, to begin with, the errors have to do with the fact that the students clearly failed to recognise that aspiration is the noise (Roach, 1992: 12) or audible breath (Crystal, 1997: 30), made when a consonantal constriction is released and air is allowed to escape relatively freely, and that this only occurs with English voiceless plosives / $\mathrm{pt} \mathrm{k} /$ at the beginning of a stressed syllable, and not in syllable-final position. Example 9, on the other hand, clearly illustrates that some of the students included in the study failed to observe that when $/ \mathrm{pt} \mathrm{k} /$ are preceded by / s/ at the beginning of a syllable they are not aspirated. The reason is simple - they are not found in the initial position of the stressed syllable any longer as they are preceded by the sound /s/. Example 7 above shows that for some students producing broad transcription for twosyllable words like supply poses no problem, including the correct stress placement, whereas the absence of the diacritic used for aspirated /p/shows that they may not have mastered their narrow transcription skills fully. Example 8 above does not only show the absence of the diacritic used for aspiration, but it also serves as an interesting, and, at times, a frequent case of incorrect vowel used.

Generally speaking, two rules can be said to exist relating to English voiceless plosives (stops), as follows:

1. Voiceless plosives / p t k/ are aspirated when they are syllable initial, as in words such as pen, ten, kick.

2. Voiceless plosives / $\mathrm{pt} \mathrm{k/} \mathrm{are} \mathrm{unaspirated} \mathrm{in} \mathrm{words} \mathrm{such} \mathrm{as} \mathrm{speck,} \mathrm{stick,}$ school. 


\subsection{Unreleased (Unexploded) Plosives}

Examples of words given to students in spelling only, including the actual narrow transcription as produced by the students:

i): $\quad$ correctly

\begin{tabular}{|c|c|c|c|c|c|}
\hline & Word & $\begin{array}{c}\text { Narrow } \\
\text { Transcription }\end{array}$ & & Word & $\begin{array}{c}\text { Narrow } \\
\text { Transcription }\end{array}$ \\
\hline 10. & apt & [æp't] & 10.b. & begged & [beg'd] \\
\hline 11. & dropped & [dropt] & 11.b. & pact & {$\left[p^{h} æ k t\right]$} \\
\hline 12. & act & [ækt] & 12..b. & cracked & {$\left[\mathrm{k}^{\mathrm{h}}\right.$ ræk $\left.\mathrm{t}\right]$} \\
\hline
\end{tabular}

and

ii) incorrectly

\begin{tabular}{|c|c|c|c|c|c|}
\hline & Word & $\begin{array}{c}\text { Narrow } \\
\text { Transcription }\end{array}$ & & Word & $\begin{array}{c}\text { Narrow } \\
\text { Transcription }\end{array}$ \\
\hline 13. & apt & [æpt] & 13.b. & begged & [begd?] \\
\hline 14. & dropped & [dra:pt] & 14.b. & pact & $\left.\left[p^{h} æ k k^{h}\right\urcorner\right]$ \\
\hline 15. & act & [ekt] & 15..b. & cracked & [krækt?] \\
\hline
\end{tabular}

\begin{tabular}{|c|c|c|c|}
\hline Academic Year & $\begin{array}{c}\text { No. of subjects test- } \\
\text { ed }\end{array}$ & YES & \% \\
\hline $2013 / 2014$ & 42 & 19 & 45.2 \\
\hline
\end{tabular}

Table 2. Identification of unreleased plosives

Table 2 clearly shows, from the statistical point of view at least, that identifying unreleased or unexploded plosives seems to pose somewhat of a problem. Only 19 students, which is less than one half of the tested students were able to identify a situation in which the release of the particular plosive can also be non-audible (Ladefoged, 2001: 58), which typically happens when a plosive is followed by another plosive, articulated at some different point. This type of release, indicated by another diacritic, a small symbol, also known as 'superscript corner' [ ' ], was successfully observed by students as shown in examples 10-12 and 10b-12b. However, examples $13-15$ and $13 \mathrm{~b}-15 \mathrm{~b}$ show the many types of errors students made in in- 
dentifying the unreleased plosive. For instance, in both examples $13 \mathrm{~b}$ and $15 \mathrm{~b}$ it was the second plosive in the two consonant cluster that was marked as not fully articulated, which is in contradiction with the general rule according to which, as Ladefoged discusses (2001: 57) the rules for English consonant allophones, English plosives are unexploded when they occur before another plosive in words such as apt, rubbed etc. In example $14 \mathrm{~b}$ both plosives are marked as not fully produced, however only the first in the series can be unreleased. In examples 13 and 14, the students failed to identify unreleased plosives in general, and, additionally, did not get the correct vowels. In example 15, there was no problem with the identification and marking of the unexploded plosive, but an incorrect initial vowel.

\subsection{Dentalisation}

Examples of words given to students in spelling only, including the actual narrow transcription as produced by the students:

i): correctly
16. eighth
[e1g $\Theta]$
17. tenth
[ten $\Theta$ ]
18. wealth
[wele]

and

iii) incorrectly

$\begin{array}{ll}\text { 19. eleventh } & {\left[\mathrm{I}^{\prime} \text { levən} \Theta\right]} \\ \text { 20. tenth } & \text { [tent] } \\ \text { 21. wealth } & \text { [vel } \Theta]\end{array}$

In comparison to the previous subsection's statistics (unreleased plosives), the figures shown below are significantly higher, showing that a vast majority of the students are able to recognise the point in speech where alveolar sounds become dental, and indicate so by using the correct diacritic.

\begin{tabular}{|c|c|c|c|}
\hline Academic Year & No. of subjects tested & YES & \% \\
\hline $2013 / 2014$ & 42 & 36 & 85.7 \\
\hline
\end{tabular}

Table 3. Identification of dentalised alveolars 
There were, however, several instances observed (some of which are presented above in examples 19, 20 and 21), where students failed to recognise the influence of a dental sound (either $/ \Theta /$ or $/ \partial /$ ) on the preceding alveolar sound, i.e. the fact that, as Ladefoged (2001: 59) states, alveolar consonants become dentals before dental consonants, as in eighth, tenth, wealth. Generally speaking, dentalisation is a phenomenon only observed in speech, and therefore indicated in narrow (phonetic) transcription. As a result of assimilation, in rapid, casual, relaxed speech, some of these dentals are quite often omitted. In example 20, the student failed to use the phonetic symbol for dental articulation (Crystal, 1997: 109), [n], placed underneath the symbol for the consonant in question, most likely because the final consonant was transcribed as the voiceless alveolar plosive $(/ \mathrm{t} /$ and not one of the two dental sounds of English. In example 19 the diacritic is missing, and in example 21, although dentalisation is clearly illustrated by the correct use of the diacritics, the student did not get the initial consonant correctly, most likely owing to the impact of their native language (in which there is no $/ \mathrm{w} /$ ).

\subsection{Velarisation}

Examples of words given to students in spelling only, including the actual narrow transcription as produced by the students:

i): $\quad$ correctly
22. smile
[smart]
23. cold
[kəutd]
24. milk
[mitk]

and

iv) incorrectly
25. smile
[smarl]
26. cold
[kəuld]
27. milk
[milk]
28. health
[helӨ]

As it can be seen in Table 4 below, the statistics clearly show that the students identify the dark /1/ in the syllable-final position (as in pull, bull, wool, etc.) better that the dark $/ 1 /$ when followed by a consonant (as in milk, spelt, etc.). 


\begin{tabular}{|c|c|c|c|c|c|}
\hline Academic Year & $\begin{array}{c}\text { No. of sub- } \\
\text { jects tested }\end{array}$ & $\begin{array}{c}\text { Syllable- } \\
\text { final }\end{array}$ & $\%$ & $\begin{array}{c}\text { Followed } \\
\text { by a con- } \\
\text { sonant }\end{array}$ & $\%$ \\
\hline $2013 / 2014$ & 42 & 35 & 83.3 & 29 & 69.0 \\
\hline
\end{tabular}

Table 4. Dark /1/ in syllable-final position vs. Dark /1/ followed by a consonant

Examples 25-28 above clearly confirm the figures shown in the table above, i.e. in all four examples the students failed to identify the different quality the English lateral consonant /1/ has in the following words cold, milk and health, where, as Roach argues (1992: 118), the /1/ phoneme is articulated with its usual primary constriction in the alveolar region, while the back of the tongue is raised as for an [u] vowel, creating a secondary constriction, as in cold and milk (where the lateral is followed by a consonant), but also in words like smile, where the lateral is in syllable-final position.

Crystal (1997: 409) essentially agrees with Roach in that velarisation is a general term referring to any secondary articulation. More particularly, it is a process involving a movement of the back part of the tongue towards the velum. Crystal argues that, for a sound to be velarised, its primary place of articulation must be somewhere else in the vocal tract (primarily the alveolar ridge). In English, velarisation depends on the context - syllable final $/ 1 /$, as in cool, is given a velar resonance, which can be compared with the syllable initial /1/, as in life, where the back of the tongue is much further forward in the vocal tract. Crystal says that a rather loose label for velar resonance sounds is 'dark', as opposed to 'clear', or 'light', used for palatal-resonance sounds. The usual symbol for velarisation (velar resonance) is [†].

\subsection{Syllabic Consonants}

Finally, Table 5 below shows that identifying syllabic / $1 /$ and /n/, as the two most frequently occurring syllabic consonants in English, is at a relatively high level. In addition, it should be highlighted here the students were not only asked to identify the syllabic consonant in question, but also to provide the transcription for the given word, thus showing their full transcription skills.

\begin{tabular}{|c|c|c|c|c|c|}
\hline Academic Year & $\begin{array}{c}\text { No. of sub- } \\
\text { jects tested }\end{array}$ & /1/ & $\%$ & /n/ & $\%$ \\
\hline $2013 / 2014$ & 42 & 31 & 73.8 & 30 & 71.4 \\
\hline
\end{tabular}

Table 5. Syllabic /l/ and /n/

Some of the words that were given to the students for broad transcription, focusing on identifying one of the syllabic consonants were: button, bottle, middle, 
kitten, mutton, fiddle, nozzle, sizzle, etc. As the figures above suggest, $73.8 \%$ of the students successfully identified /1/ as being syllabic, i.e. those that can stand alone as a syllable, and indicated them correctly, either by using a small raised schwa in front of the consonant in question, or by a small vertical line underneath the consonant. As for the syllabic /n/, the situation was almost identical, with only one student less successful in identifying and marking the syllabic /n/, compared to syllabic /1/.

\subsection{Coalescent Assimilation}

Here are some of the examples the students were presented with, and required to identify the type of assimilation:

29. Meet you at 6 p.m.

30. Did you do this?

31. Miss you terribly.

32. Buzz you later.

Table 6 below shows that 78.5 subjects successfully identified the case of coalescent assimilation for the alveolar plosive par $/ \mathrm{t} d /$, and the exact same number of subjects identified the same phenomenon with the alveolar fricative par /s z/. Student failing to identify the type of assimilation in this case mistook it for other types of assimilation, labelling it assimilation of place or manner, or simply left the question unanswered,

\begin{tabular}{|c|c|c|c|c|c|c|}
\hline Academic Year & $\begin{array}{l}\text { No. of sub- } \\
\text { jects tested }\end{array}$ & $\begin{array}{c}/ t / \\
+ \\
/ j /\end{array}$ & $\begin{array}{c}/ \mathrm{d} / \\
+ \\
/ \mathrm{j} /\end{array}$ & $\begin{array}{c}\text { /s/ } \\
+ \\
/ j /\end{array}$ & $\begin{array}{c}\mid \mathrm{z} / \\
+ \\
/ \mathrm{j} /\end{array}$ & $\%$ \\
\hline $2013 / 2014$ & 42 & 33 & 33 & 33 & 33 & 78.5 \\
\hline
\end{tabular}

Table 6. Identification of coalescent assimilation (the four cases)

In other words, more than three quarters of the students were successful in identifying the type of assimilation according to direction and/or aspect, which occurs when two sound combine to form a different one. This chiefly happens with $/ \mathrm{t}, \mathrm{d}, \mathrm{s}, \mathrm{z} /+/ \mathrm{j} /$ resulting in $/ \mathrm{t} \mathrm{d} \int \mathrm{s} /$ respectively. This process occurs most frequently in English when final alveolar consonants such as /s, z/ and //t, d/ are followed by initial palatal $/ \mathrm{j} /$. Then they become palatalized fricatives and affricates, respectively (Celce-Murcia, 1996: 163):
$/ \mathrm{s} / \mathrm{j} / \mathrm{j}=\mathrm{s} / \mathrm{s} /$
issue
$/ \mathrm{z} /+\mathrm{j} /=>/ 3 /$
pleasure 
He's coming this year.

$$
/ \mathrm{t} /+\mathrm{j} / \quad=>/ \mathrm{t} /
$$

Stature

Is that your dog?
Does your mother know?

$$
\begin{aligned}
& / \mathrm{d} /+/ \mathrm{j} / \quad=>/ \mathrm{d} / \\
& \text { procedure } \\
& \text { Would you mind moving? }
\end{aligned}
$$

\section{Conclusion}

In this paper I have taken a closer look at what happens to a number of English consonants in connected speech. One of the reasons I decided to focus on the aspirated and unreleased plosives, dentalisation, velarisation and syllabic consonants is the fact that for most non-native speakers of English these actually pose difficulty to a certain extent.

This primarily concerns aspirated and unexploded plosives of English, as well as syllabic consonants, and then to a slightly lesser degree velarised and dentalised consonants.

Secondly, I felt I needed to outline the types of transcription and introduce and exemplify the various diacritical signs that exist in phonetics, in order to empower any university students of English that may show particular interest in this field. Following is a brief summary:

1. Generally speaking, as we speak (rapid, relaxed, casual, connected speech), a number of phonetic phenomena occur. Not every single sound that we produce sounds exactly the same in a given environment. The presence of allophones presents clear evidence in support of that claim.

2. Aspiration $\left[{ }^{\mathrm{h}}\right]$ : any of the three voiceless (unvoiced) English plosives, / $\mathrm{p}$ $\mathrm{t} \mathrm{k} /$ is aspirated when it is found in the initial position of a stressed syllable. Aspiration is a term denoting a slight 'explosion' of air which occurs when the air-stream is suddenly released from the vocal tract (the mouth), having been compressed behind the obstacle (e.g. in the case of /p/ and /b/, the lower lip and the upper lip present the obstacle.

3. Unreleased plosives [ $[$ ]: English plosives, regardless of their voicing, can be unreleased (unexploded). This only occurs when a plosive is followed by another plosive in the word-final position. In other words, the preceding plosive may not be fully released, leaving the other being the only plosive that is clearly heard.

4. Dentalisation $\left[_{n}\right]$ : English alveolar consonants are easily dentalised in front of dental sounds / $\mathrm{T} /$ and $/ \Delta /$, both at word level and at word boundaries (in which case assimilation of place is observed). This means that the sounds preceding the dental sound in question change their place of articulation 
(which is chiefly the alveolar ridge) and become dental, as they are modified by the following dental sound.

5. Velarisation [ $\nmid$ ]: The English lateral consonant /1/ may have at least two qualities, depending on its environment (two allophones as different realisations of the same phoneme /1/). When /1/ is in the syllable-initial position there is no velarisation as the front part of the tongue (the tip) is quite close to the alveolar ridge, being its place of articulation. However, the front part of the tongue curls slightly backwards when $/ 1 /$ is in the word-final position or when it is followed by another vowel. In this case we talk of velarisation as the front part of tongue is quite close to the velum (soft palate).

6. Syllabic consonants: Four English consonants / $1 \mathrm{n} \mathrm{m} \mathrm{r} \mathrm{/} \mathrm{may} \mathrm{stand} \mathrm{as} \mathrm{a} \mathrm{syl-}$ lable on their own. The former two are more frequently found being syllabic. Syllabicity is indicated by a special diacritic - a small raised schwa in front of the consonant in question or by a small vertical line just underneath it. Syllabic consonants are a result of the loss of the weak vowel schwa in casual, relaxed, connected speech.

In this paper I have also presented the results of the study undertaken, providing the statistical overview, discussion and analysis concerning the topics dealt with in the sections and subsections of this paper. More specifically, as introduced in Sections 1 and 3, the study examined a total of 42 students who enrolled in the English Department at the Faculty of Philosophy, University of Tuzla in the academic year 2013/2014.

The results and the analysis that accompany each subsection of Section 4 clearly indicate the level to which the students, having come from their respective high school backgrounds with very little or no skills in English Phonology and Phonetics, showing that:

- they have developed a strong sense of elementary terms in the field, and their use

- they have developed an understanding of the English sound system and articulation of sounds in general

- a vast majority of them have mastered the use of English phonemic symbols

- they have developed transcription skills, including broad and narrow transcription

The table below provides the statistical summary of the study comprising the data collected and analysed for the academic year 2013/14: 


\begin{tabular}{|l|c|}
\hline & $\begin{array}{c}\mathbf{2 0 1 3 / 1 4} \\
\mathbf{( \% )}\end{array}$ \\
\hline Coalescent assimilation & 78 \\
\hline Aspiration & 69 \\
\hline Unreleased plosives & 45 \\
\hline Dentalisation & 85 \\
\hline Velarisation* & 76 \\
\hline Syllabic consonants & 72 \\
\hline \multicolumn{2}{|c|}{ Table 7. Overall statistical overview } \\
\hline
\end{tabular}

It can be said that the results are quite satisfactory, as in most of the situations it well above $50 \%$ that the particular allophones were identified. Signalling a potential problem area is the average of $45 \%$ successfully identified cases of unreleased plosives.

As for velarisation, the asterisk suggests that the students were slightly more successful in identifying dark /1/ when found in the syllable-final position (83\%), as opposed to the $69 \%$ who identified dark /1/ when followed by another consonant.

In terms of syllabic consonants, for the purposes of the study, we looked into the most frequent cases of syllabic $/ \mathrm{l} /$ and $/ \mathrm{n} /$, where the students did slightly better when it comes to identifying syllabic /l/ (73\%) than syllabic /n/ (71\%).

To conclude with the one type of assimilation the study looked into (coalescence), the results clearly indicate that almost only $20 \%$ of the cases of coalescence were not identified by the students. In fact, both the fricative pair /s z/ and the alveolar pair $/ \mathrm{t} \mathrm{d}$ / produced the same statistics (app.80\%), suggesting that the students can easily recognise this phenomenon.

The present study may serve as a starting point for further related study, with a view to determining the acquisition of English Phonology and Phonetics related issues for English students.

On a general note, the study also signals major issues in secondary English education, where more attention ought to be given to issues traditionally dealt with by English Phonology and Phonetics.

\section{References}

Celce-Murcia, Marianne, Donna M. Brinton, \& Janet M. Goodwin (1996). Teaching Pronunciation. A Reference for teachers of English to Speakers of Other Languages. Cambridge: Cambridge University Press.

Crystal, David (1997). A Dictionary of Linguistics and Phonetics, Oxford: Blackwell.

Gomes de Matos, Francisco (2002). Second language learners' rights. In Cook, Vivian (ed.) Portraits of the L2 User. Clevedon: Multilingual Matters, 303-323. 
Handbook of the International Phonetic Association (1999). Cambridge: Cambridge University Press.

Josipović, Višnja (1999). Phonetics and Phonology for Students of English. Zagreb: Targa.

Ladefoged, Peter (2001). A Course in Phonetics, Fourth edition. Boston: Heinle and Heinle.

Lintunen, Pekka (2005). Phonemic Transcription and its Effect on Learning. University of Turku, Finland.

Roach Peter (1992). Introducing Phonetics. London: Penguin English.

Wells, John C (1996). Why phonetic transcription is important. Journal of the Phonetic Society of Korea 31-32: 239-242.

Wells, John C. (2001). Longman Pronunciation Dictionary. Harlow: Pearson.

Received June 23, 2014

Accepted for publication October 29, 2014

Author's address:

Sanel Hadžiahmetović Jurida

English Department

Faculty of Philosophy

University of Tuzla

Ul. Dr. Tihomila Markovića 1

75000 Tuzla, Bosnia and Herzegovina

e-mail: sanel.h.jurida@untz.ba 